\title{
Exploring the Link between Employee Relationship Management and Organisational Citizenship Behaviour
}

\author{
Dr. Anietie Peter Akpan ${ }^{1 *}$, Mr. Andrew Amuamuziam Okwudu², Mr. Orok A. Imagha ${ }^{3}$ \\ ${ }^{1,3}$ Department of Business Management University of Uyo, Uyo Akwa Ibom State Nigeria \\ ${ }^{2}$ Department of Marketing University of Uyo, Uyo Akwa Ibom State Nigeria
}

DOI: $10.36348 /$ sjef.2021.v05i04.005

| Received: 07.03.2021 | Accepted: 03.04.2021 | Published: 11.04.2021

*Corresponding author: Dr. Anietie Peter Akpan

\section{Abstract}

Relationship management is seen as key to organizational productivity; as such this study was designed to explore the link between relationship management and organizational citizenship behaviour (OCB). The elements of employee relationship management under study were trust, communication, commitment, conflict management and teamwork. Data for this study were collected from 217 respondents using a structured questionnaire. Data collected were analysed using descriptive statistics, Pearson's correlation, partial correlation and multiple linear regressions. Results of analysis support both hypotheses of the study. Based on the results, it is concluded that good employee relationship management brings about increased employee performance of organizational citizenship behavior (OCB) in organisations. Consequently, it is recommended, among other things, that managers should strive to build good relationships with employees and manage same properly to reap the benefits thereof.

Keywords: Relationship management, Organizational citizenship behaviour, OCB, Trust, Communication, Conflict management, Teamwork.

Copyright (C) 2021 The Author(s): This is an open-access article distributed under the terms of the Creative Commons Attribution 4.0 International License (CC BY-NC 4.0) which permits unrestricted use, distribution, and reproduction in any medium for non-commercial use provided the original author and source are credited.

\section{INTRODUCTION}

Employees are the major assets of an organization; effective Employee Relationship Management (ERM) is essential in ensuring employees perform together as a collective unit and contribute equally towards the realization of a common goal. Limited task can be accomplished if the individuals are engaged in constant conflicts and misunderstandings. Employee relations management ensures workplace issues are handled effectively and expediently in order to remove barriers to successful job performance and foster a positive work environment.

Employee Relationship Management is a tool and a strategic process to manage and increase motivation in the workforce by increased focus on continuous perfection of the individual relationships between the employer and each employee [1]. Management of interpersonal relationships can aid the management of individual motivation levels. This implies the existence of a distinctive set of guiding principles, written or otherwise, which set parameters to and signposts for management's action regarding the way employees are treated and how particular events are handled [2]. One of the major objectives of employee relationship management is to establish and nurture harmonious relationships between organization management and employees for the achievement of organizational goals.

Effective employee relationship management requires cooperation between managers, representatives and employees [3]. This calls for development of policies that may help in maintaining fairness and efficiency in the work place. Good relationships between employers and employees do not just happen; they are the result of activities and practices that encompass key elements of employee relations management design to improve relationship between employees and management. These key elements as defined by [4] include trust, communication, commitment, conflict management and teamwork. According to [4], these employee relationship management practices have different effects on the work of an organization. One of such effects is that it enhances organizational citizenship behavior among employees in an organization [5].

Organisational citizenship behavior (OCB) are discretionary behaviours employees exhibit to help 
Anietie Peter Akpan et al., Saudi J Econ Fin, Apr, 2021; 5(4): 164-172

others and benefit the organization. Discretionary here implies that the behavior is not enforceable and not part of the formal role in terms of the person's contract with the organization [6]. OCB can be classified into two namely; Organizational citizenship behavior directed towards organization (OCB-O) and Organizational citizenship behaviour directed towards individuals within the Organisation (OCB-I). For instance, citizenship behaviours directed at the organization include such actions as adhering to informal rules designed to maintain order, demonstrating above average work attendance, and not taking extended work breaks. Citizenship behaviours that are more personally focused on helping specific individuals include such actions as assisting others who have been absent, helping colleagues who have heavy workloads, and taking a personal interest in the well-being of other employees.

Bajaj, R., Sinha, S., et al. [7] noted that given the effect of employee relationship management practices on firms' outcomes, it has become a strategic necessity for attracting and retaining highly valued employees. However, despite the vital role of employee relationship management, some previous studies have been criticised for concentrating mostly on the general effect of relationship management on employees or organisational performance. None of those studies have looked at employee relationship management from the point trust, communication, commitment, conflict management and teamwork, nor have they shown the relative contribution of these key practices to employee citizenship behaviour. This study seeks to contribute to filling this gap by examining the relationship between the above defined practices of employee relationship management and employee citizenship behaviour.

\section{REVIEW OF RELATED LITERATURE Employee Relationship Management}

In a general sense, employee relationship management is understood to be a strategy, programs and technology to effectively manage how firms relate to prospective, current and former employees. More specifically, employee relationship management is defined as a process that organisations use to effectively manage relationship between employer or the representative manager and employees, aimed towards maintaining commitment, morale and trust so as to create productive and secure workplace environment [8]. Also, it can be defined as the process of adopting various controlling methods and practices to regulate employer-employee relationship and/or employeeemployee relationship, which enable the company to achieve its goals [9]. Furthermore, employee relationship management is all about effective organizational communications, which can build employee confidence, trust and loyalty, enabling managements to realize the potential of the skills and knowledge within the organization [10].
According to Eli [11] management of interpersonal relationships can aid the management of individual motivation levels. This implies the existence of a distinctive set of guiding principles, written or otherwise, which set parameters for management action regarding the way employees are treated and how events are handled [2]. The objective of employee relationship management is to establish and nurture harmonious relationships between organization management and employees for the achievement of organizational goals. For it to be effective, it requires cooperation between managers, representatives and employees [3]. This calls for development of policies that help to maintain fairness and efficiency in the work place. Good management of employee relations in any business unit ensures schemes for rewards and recognition, transparent communication system and proper care towards employee grievances. Best employee relationship management practices incorporate labor and employment laws, resourcefulness and human resource expertise in developing practices that improve working relationships [12].

\section{Organisational Citizenship Behaviour}

Organisational citizenship behaviour consists of those behaviours that extend beyond specific role requirements, with the stipulation that such behaviours are performed voluntarily without expectation of material or social rewards [13]. Although organisational citizenship behaviours promote organisational effectiveness, they are not explicitly recognized in an organisation's reward system. In defining OCB and its benefits, [14] explains OCB as?

...individual behaviour that is discretionary, not directly or explicitly recognized by the formal reward system and that in the aggregate promotes the effective functioning of the organisation. By discretionary we mean that the behaviour is not an enforceable requirement of the role or the job description, that is the clearly specifiable terms of the person's employment contract with the organisation; the behaviour is rather a matter of personal choice, such that its omission is not generally understood as punishable....and that returns not be contractually guaranteed by any specific policies and procedures.

Thus, according to [14] definition, organisational citizenship behavior has at least three characteristics: it is discretionary; it is not directly or explicitly recognized by the formal reward system; and in the aggregate, the behaviour promotes the effective functioning of the organisation.

Others have supported this definition. For instance [15], in accordance with [14], directed at individuals, groups, and/or organisations, that are not formally prescribed nor are they directly rewarded. Further to this [16], suggest that, to be considered as 
Anietie Peter Akpan et al., Saudi J Econ Fin, Apr, 2021; 5(4): 164-172

OCB, these behaviours must be voluntary, intentional, positive, and must benefit others.

According to [17], OCBs are important because effective organisational functioning requires employees not only to perform their prescribed role (referred to as in-role behaviours), but also to engage in behaviours that go beyond these formal obligations [18] also argued that citizenship behaviours are important because they lubricate the social machinery of the organisation. They provide the flexibility needed to work through many unforeseen contingencies and enable participants to cope with the otherwise awesome condition of interdependence on each other. Further to this [19] state that OCB is essential because organisations cannot anticipate through formally stated in-role job descriptions the entire array of behaviours needed for achieving organisational goals. In agreement with these [20] opined that, though organisational citizenship behaviours are not part of individuals' assigned duties, they are still beneficial to the organisation, its members and the employees themselves.

Several authors have discussed the potential impact of OCBs on organizational success. For instance [21] opine that organisational citizenship behaviour has been associated with improvements in manager evaluations of individual performance and enhanced organizational performance. Furthermore [22] indicate that OCBs may contribute to organisational success by: enhancing co-worker and managerial productivity; freeing up resources so they can be used for more productive purposes; reducing the need to devote scarce resources to purely maintenance functions; helping to coordinate activities both within and across work groups; strengthening the organisation to adapt more effectively to environmental changes; contributing to organisational performance because these behaviours provide an effective means of managing the interdependencies between members of a work unit, and as a result increase the collective outcome and achieved; and increasing organisational productivity because workers that exhibit such behaviour improve the ability of co-workers to perform their jobs as such behaviour allows managers to devote more time to productive activities like planning, scheduling, problem solving and organisational analysis.

In the aggregate, OCBs tend to increase the organisation's efficiency and effectiveness, adding significantly to overall positive performance evaluations and reward recommendations. OCB has been linked to organisational survival and excellence, and benefits include promotion of positive relationships among employees, providing the flexibility needed for innovation and guiding the efficient use of scarce resources [18].

There is OCB that benefits individuals (OCBI) and OCB that benefits the organisation as a whole
(OCB-O). McNeely and Meglino found that OCB-I is related to individual dispositions such as empathy, while OCB-O is related to organisational context. In their study [21], decomposed OCB into two dimensions; citizenship behaviors which are intended to benefit the organization (OCB-O) and citizenship behaviors which are intended to benefit specific individuals within the organization, especially coworkers (OCB-I). According to them, OCB-I include such behaviours like helping behavior and selfdevelopment whereas OCB-O include such behaviours like sportsmanship, organizational loyalty, organizational compliance, individual initiative and civic virtue.

Giving a contrary opinion [4], says that the there is no clear demarcation between the behaviours that constitute OCB-I and those that constitute OCB-O. $\mathrm{He}$ explains that behaviours that benefit individual in a particular context may be beneficial to organization given a different context. For instance, citizenship behavior like personal development is beneficial to the individual in the sense that it enhances the individual competences. However, in a different context, it is beneficial to the organization in that it adds to the employee performance and affects, positively, the overall organizational performance. OCB at any time affects both the organization and the individual. It can be negative or positive.

\section{Elements of Employee Relationship Management and Organisational Citizenship Behaviour i. Trust}

According to [23], trust is an expectation that another party will not allow you to be harmed at a time when you are vulnerable. Your willingness to trust another party is affected by your history with that party and your personality [24]. Define trust as the extent to which one is willing to attribute good intention to and have confidence in the words and actions of others. Any positive working relationship and by extension OCB is based on trust. An environment of trust assumes that both parties will be safe, and it carries with it an implicit message that you have each other's best interest in mind [23]. Note that as we become familiar with an individual or a group, we gradually allow ourselves to be vulnerable to them and as long as no injury comes from that vulnerability, our trust increases. However, sometimes some people advertently or otherwise, violate this trust. The violations of trust breach the confidence and belief we repose in them and we feel they have let us down and disappointed. An employee who finds him or herself in this situation is not likely to cooperate with co-workers, and spends valuable time and psychological resources to verify information from the distrusted party. One is also inclined to be careful not to share too much information with them [23]. This situation would invariably harm the working relationship and people would not be willing to go beyond their formal job requirements. 
Anietie Peter Akpan et al., Saudi J Econ Fin, Apr, 2021; 5(4): 164-172

Furthermore, trust is being defined as a perceived assumption of an acknowledged or accepted duty to protect the rights and interests of others [25]. Specifically, authors recognized the importance of trust in risk taking [26-29]. Found that trust would lead to risk taking in an interpersonal relationship. The amount of risk an employee takes in an interpersonal exchange is related to the amount of trust they feel towards that individual [29].

Following the inclusion of the relationship between risk taking and inter personal trust, research began to include 'growth of trust in the organizational sector [30]. Posit that when employees trust in the organization, a number of positive outcomes occur: free exchange of information, high involvement, helpseeking behaviour, high confidence in others, broad role definitions, and communal relationships.

\section{ii. Commitment}

Gefen D and Carmeli A [31] identify three distinct themes in defining commitment as 'affective', 'continuance' and 'normative' commitment. They define affective commitment as when an employee strongly identifies with the goals of the organisation and desires to remain a part of the organisation. While continuance commitment is a desire for an employee to stay with the organization because you believe you have to be part of the organization. Normative commitment is when an employee views his or her obligation to remain with the organization as the 'right or moral thing to do'.

Ogaard $\mathrm{T}$ [32] reported a higher correlation between commitment and performance through organizational citizenship behavior and in-role behaviour [33]. Reported a significant difference in commitment between contingent and permanent staff in organisation. The results suggested that permanent staff showed more commitment and report stronger identification with the organization, and organization citizenship behaviour was found to be positively related to affective commitment and identification for the permanently employed staff [34]. found a significant relationship between commitment and work outcome in their studies specifically addressing the relationship between affective commitment and OCB in organisations.

\section{iii. Communication}

Honest communication is critical in
establishing strong employee relationships. Management must be committed to communicating regularly and honestly with employees about the issues that impact their work. The more open organizations can be, the more likely they are to establish strong relationships that lead to increased loyalty and enhanced performance among employees. Communication is the human activity that links people together and creates relationship [35]. This means that individuals relate with each other by means of communication. It is a bond that binds people together in an organization. Different units exist in an organization, and it is through communication that interaction takes place for the attainment of organizational goals [4]. Asserts that communication constitutes the action of the organization and the works of organizing, coordinating, informing, arranging, staffing, and other functions of management. Communication is vital in organizations such that [10] argues that communication has a vital role in the failure or accomplishment of any organization.

Communication in the organization can be formal or informal [2]. Formal communication follows the formal structure or hierarchy of the organization [9], and can flow in downward, upward, and cross-wise directions [12]. Downward communication flows from people at higher levels to those at lower levels in the organization hierarchy; upward communication travels from subordinates to superiors and continues up the organizational hierarchy; while cross-wise communication flows among people on the same organizational levels, and among people at different levels who have no direct reporting relationships with one another. Informal communication, on the other hand, is based on social relationships and is inevitable in organizational life [19]. Informal communication channels such as grapevine and gossips often fill the gaps that formal communication fails to address [11]. While informal communication originates to serve employees' private purposes, formal communication is supposed to serve the purpose of the organization [1]. On the whole, both forms of communication are important; both encourage OCB and should be managed properly to enhance organizational effectiveness.

\section{iv. Conflict}

Conflict management is the practice of recognizing and dealing with disputes in rational, balanced and effective way. When conflict management procedure is stated clearly in an organization, there will be development of employee citizenship behaviour. Conflict managementis the ability to handle conflict efficiently. Conflict handling refers to the methods used by anyone or groups to deal with conflicts [3]. These methods include integrating, compromising, obliging, avoidance and dominating.

According to [8], when there are proper procedures to managing conflict in an organization, employee trust in the system is enhanced. This has a direct correlation with OCB in that when employee trust the system to be fair on them whenever there is a conflict, they will go above and beyond their prescribed duties and engage in OCB, be it for the benefit of individuals within the organization (i.e. OCB-I) or the organization (i.e. OCB-O). 


\section{v. Teamwork}

Nowadays, many organizational divisions have adopted the culture of teamwork as key to achieve greater performance. Teamwork was previously viewed as the actions of employees brought together to attain a certain objective or goal by placing the interests of each member to the interest of the overall group [18]. Similarly [32], thought about teamwork as a group of people working together in order to attain a common goal. The author indicated that teams in organizations usually consist of employees who acquire necessary skills that are important to achieve the desired objectives. In this regard, all team members have the opportunities to teach each other how to perform a particular task skillfully and professionally thereby enhancing OCB. Hence, the greater the degree of collaboration among team members, the higher the opportunity for OCB through shared learning. Past studies found that teamwork has significant positive effect on employee productivity and organizational performance. That is, organizations which emphasize more on teams can enjoy favourable outcomes such as enhanced organizational performance through employees' display of in-role behavior and OCB [7]. Moreover, [28] confirmed that teamwork enriches performance through the increased scope of using employees' knowledge, skills, and abilities and sharing them with other members. This effort of sharing, they noted, is not part of an employee's job description, but extra role played by the employee. They concluded by saying that teamwork enhances employee display of OCB.

\section{Study Hypotheses}

i. There is significant relationship between employee relationship management and OCB

ii. Employee relationship management is more strongly related to the performance of OCB-O than to OCB-I.

\section{METHODOLOGY}

The survey research design was adopted for this study. The study was conducted in deposit money banks located in Uyo, Akwa Ibom State in the Niger Delta region of Nigeria. The target population of the study comprised all permanent employees of the banks and their supervisors. A total of 217 employees (i.e. 181 subordinates and 36 supervisors) completed and returned the copies of questionnaire that were administered. Participation in this study was voluntary.
Employee relationship management was measured using the five elements of employee relationship management as proposed by [4]. These elements are trust, communication, commitment, conflict management and teamwork. The items comprising these elements were adapted from [24] and [15]. Cronbach's alpha for the items that make up the elements in the adapted scale was 0.81 . For each of the items, respondents were asked to assess the extent of agreement or disagreement with the items on a scale of 1 to 5 , where 1 represents strongly disagree and 4 strongly agree.

Organisational Citizenship Behaviour (OCB): Supervisors provided their evaluation of the employees' OCB along two dimensions. These dimensions where organizational citizenship behaviors directed toward the whole organization (OCB-O), and organizational citizenship behaviors directed at other individuals (OCB-I). The two dimensions of OCB were assessed using 12 items developed by Williams and Anderson (1991). In each case, responses were given on a 5-point scale ranging from 1 (Strongly Disagree) to 5 (Strongly Agree). Cronbach's alphas for the six items in OCB-O scale was 0.75 and the six items in OCB-I scale was 0.79.All of the OCB items were examined using Confirmatory Factor Analysis (CFA). A two-factor model with a chi-square coefficient of 237.44 and a degree of freedom of 128 fit the data reasonably well, and all items loaded significantly onto their specified factor. The key fit indices were as follows: GFI $=0.82$, RMSEA $=0.76, \mathrm{CFI}=0.95$ and TLI $=0.91$. Moreover, this two-factor solution fit the data significantly better than a one-factor model which had a chi-square coefficient of 462.38 and a degree of freedom of 131.

\section{RESULTS AND INTERPRETATION}

As stated earlier, respondents for this study were 217 employees (i.e. 181 subordinates and 36 supervisors) of money deposit banks. Demographic data collected from respondents indicates that the average age of subordinates was 34 years, and the average duration spent with the organisation was approximately six years. Out of the 161 subordinates, $55.3 \%$ were male and $44.7 \%$ were female. Theaverage age of supervisors was 46 , and the average duration spent with the organisation was approximately 12 years. Out of the 36 supervisors, $69.6 \%$ were male and $30.4 \%$ were female. 
Anietie Peter Akpan et al., Saudi J Econ Fin, Apr, 2021; 5(4): 164-172

Table-1: Descriptive Statistics

\begin{tabular}{|l|l|l|l|l|}
\hline Employee relationship management factors & N & Mean & Standard deviation & Standard error \\
\hline Trust & 217 & 3.470 & .438 & .058 \\
\hline Communication & 217 & 3.761 & .404 & .044 \\
\hline Commitment & 217 & 3.513 & .511 & .073 \\
\hline Conflict management & 217 & 3.212 & .451 & .131 \\
\hline Teamwork & 217 & 3.129 & .468 & .153 \\
\hline OCB-I & 217 & 3.342 & .411 & .051 \\
\hline OCB-O & 217 & 3.337 & .432 & .112 \\
\hline
\end{tabular}

Table 1 indicates the mean, standard deviation and standard error of the employee relationship management factor under study. It shows that the mean for all the factors is between 3.129 and 3.761. The fourth column shows the standard deviation which measures how well the mean represents the data. According to Table 1, the standard deviation is 0.438 for trust, 0.404 for communication and 0.511 for commitment. Others are 0.451 for conflict management.
0.468 for teamwork, 0.411 for OCB-I and 0.432 for OCB-O. The standard deviations from this result indicate that the mean is a good representation of the data. The fifth column illustrates the standard error, which is a measure of how representative a sample is likely to be of the population. According to the table, the standard error scores are relatively small ranging from 0.058 for trust to 0.153 for teamwork and others in-between those two.

Table-2: Results of Pearson Correlation Analysis $(n=217)$

\begin{tabular}{|l|l|l|l|}
\hline \multirow{3}{*}{ Trust } & & OCB-O & OCB-I \\
\hline \multirow{3}{*}{ Communication } & Pearson Correalation & $.566^{* *}$ & $.427 * *$ \\
\cline { 2 - 4 } & Sig. (2-tailed) & .000 & .000 \\
\hline \multirow{3}{*}{ Commitment } & Pearson Correalation & $.680^{* *}$ & $.519 * *$ \\
\cline { 2 - 4 } & Sig. (2-tailed) & .000 & .000 \\
\hline Conflict management & Pearson Correalation & $.012^{* *}$ & $.009 * *$ \\
\cline { 2 - 4 } & Sig. (2-tailed) & .000 & .022 \\
\hline \multirow{3}{*}{ Teamwork } & Pearson Correalation & $.400^{* *}$ & $.237^{* *}$ \\
\cline { 2 - 4 } & Sig. (2-tailed) & .000 & .000 \\
\cline { 2 - 4 } & Pearson Correalation & $.421^{* *}$ & $.369 * *$ \\
\cline { 2 - 4 } & Sig. (2-tailed) & .000 & .000 \\
\hline
\end{tabular}

**Correlation is significant at 0.05 levels (2-tailed)

Table 2 shows the correlation between variables. The result reveals that there are significant positive correlations between trust and OCB-O $(\mathrm{r}=0.566, \mathrm{p}<0.000)$, communication and OCB-O $(\mathrm{r}=0.680 \mathrm{p}<0.000)$, teamwork and OCB-O $(\mathrm{r}=0.421, \mathrm{p}<0.000)$, and conflict management and OCB$\mathrm{O}(\mathrm{r}=0.400, \mathrm{p}<0.000)$. However, commitment $(\mathrm{r}=0.012$, $\mathrm{p}<0.000)$ had a weak correlation with OCB-O. The level of relationship between employee relationship management variables and OCB-I relative to OCB-O was slightly lower in all variables of employee relationship management. As can be seen from Table 2, there is a positive and strong relationship between trust and OCB-I $(r=0.427, \mathrm{p}<0.000)$, communication and OCB $-\mathrm{I}(\mathrm{r}=0.519 \mathrm{p}<0.000)$, and teamwork and OCB-I $(\mathrm{r}=0.421, \mathrm{p}<0.000)$. Commitment and OCB-I $(\mathrm{r}=0.009$, $\mathrm{p}<0.022)$ and conflict management and OCB-I $(\mathrm{r}=0.237, \mathrm{p}<0.000)$ both showed weak but positive relationship.

\section{Test of Hypothesis One}

Hypothesis one was tested using the multiple linear regression. The results of multiple linear regression analysis is as shown in Table 2

Table-3: Results of Multiple Regression Analysis

Model Summary

\begin{tabular}{|lllll|}
\hline Model & R & R square & Adjusted R square & Std. Error of the Estimate \\
\hline 1 & $.727^{\mathrm{a}}$ & .528 & .517 & .60598 \\
\hline
\end{tabular}

a Predictors: (Constant), Trust, Communication, Commitment, Conflict management, Teamwork 
Anietie Peter Akpan et al., Saudi J Econ Fin, Apr, 2021; 5(4): 164-172

\begin{tabular}{|lllllll|}
\hline \multicolumn{8}{|c|}{ ANOVA $^{\mathbf{b}}$} \\
\hline Model & & Sum of Squares & Df & Mean Sum of Squares & F & Sig. \\
\hline 1 & Regression & 86.757 & 5 & 17.351 & 47.251 & $.000^{\mathbf{b}}$ \\
& Residual & 414.81 & 211 & .367 & & \\
& Total & 508.38 & 216 & & \\
\end{tabular}

a Predictors: (Constant), Trust, Communication, Commitment, Conflict management, Teamwork

b. Dependent Variable: OCB

\begin{tabular}{|lllllll|}
\hline \multicolumn{7}{c|}{ Coefficients } \\
\hline & & $\begin{array}{l}\text { Unstandardised } \\
\text { Coefficient }\end{array}$ & & $\begin{array}{l}\text { Standardised } \\
\text { Coefficient }\end{array}$ & T & Sig. \\
\hline Model & Beta & $\begin{array}{l}\text { Std. } \\
\text { Error }\end{array}$ & Beta & & \\
\hline 1 & & .397 & & 1.764 & .079 \\
& & .700 & .090 & .185 & 3.598 & .000 \\
& (Constant) & .326 & .066 & .492 & 7.602 & .000 \\
& Trust & .502 & .080 & .059 & 1.224 & .222 \\
& $\begin{array}{l}\text { Communication } \\
\text { Commitment }\end{array}$ & .098 & & & 3.595 & .000 \\
& $\begin{array}{l}\text { Conflict } \\
\text { Management } \\
\text { Teamwork }\end{array}$ & .223 & .062 & .295 & 2.3401 & .020 \\
\hline
\end{tabular}

a. Dependent Variable: OCB

The results in Table 2 support hypothesis one. From Table 2, the values of $\mathrm{R}$ square $(0.528)$ and $\mathrm{R}$ (0.727) show that there is significant relationship between the independent variables and the dependent variable. This implies that $52.8 \%$ of OCB can be predicted by the relationship management variables understudy. Also, the $F$ value of 47.251 and $\mathrm{p}<0.05$.indicate that there is significant relationship between trust, communication, commitment, conflict management, teamwork and OCB. Furthermore, it can be seen that the independent variable trust has an unstandardized beta coefficient of 0.326 , communication has 0.502 , commitment 0.098 , conflict management 0.223 and teamwork 0.118 . These indicate that holding every other variable constant, a unit improvement in trust will yield $32.6 \%$ improvement in the practice of OCB by employees. Also, a unit improvement in communication, commitment, conflict management and teamwork will yield an improvement of $70.2 \%, 9.8 \%, 22.3 \%$ and $11.8 \%$ respectively on OCB. From the results, the regression model is given as:

$\mathbf{O C B}=0.700+0.326 \mathrm{X}_{1}+0.502 \mathrm{X}_{2}+0.098 \mathrm{X}_{3}+$ $0.223 \mathrm{X}_{4}+0.118 \mathrm{X}_{5}+\mathrm{e}$

\section{Test of Hypothesis Two}

Hypothesis two was tested by analyzing the difference between the strengths of dependent correlations. This was done by comparing the strength of the relationship between the dimensions of employee relationship management and the two types of organizational citizenship behavior (i.e. OCB-O and OCB-I) using partial correlations as outlined by Steiger 1980 and Cohen and Cohen 1983. The result of the partial correlation are shown in Table 4

Table-4: Partial correlation results between employee relationship management and OCB

\begin{tabular}{|l|l|l|l|}
\hline Employee Relationship Management & OCB - O & OCB - I & T \\
\hline Trust & .29 & .17 & $2.01^{*}$ \\
\hline Communication & .43 & .26 & $1.78^{*}$ \\
\hline Commitment & .19 & .10 & $2.56^{*}$ \\
\hline Conflict management & .24 & .13 & $2.23^{*}$ \\
\hline Teamwork & .26 & .14 & $2.13^{*}$ \\
\hline \multicolumn{2}{|l}{} \\
\hline
\end{tabular}

As shown in Table 4, the difference in strength of the correlations between employee relationship management variables and the OCB variables were significant. In each case, the extent of employee relationship management was more strongly related to OCB - O than to OCB - I. These results support hypothesis two which says that employee relationship management is more strongly related to the performance of OCB-O than to OCB-I.

\section{Discussion of Findings}

This study was predicated on two hypotheses. The first hypothesis was to examine the relationship between employee relationship management and OCB. The results of analysis obtained support the general idea that employee relationship management is positively related to OCB. Specifically, all employee relationship management variables were positively related to OCB. However, taking the variables individually, 
Anietie Peter Akpan et al., Saudi J Econ Fin, Apr, 2021; 5(4): 164-172

communication, trust and conflict management contribute the more to OCB in the studied organisations than other variables (see Table 3). Thus, at least among the individuals that make up the organizations in the study, it appears that employee relationship management in terms proper communication, building trust and conflict management are more important predictors of their performance of organizational citizenship behavior than teamwork and commitment.

The second hypothesis was to examine whether employee relationship management is more strongly related to the performance of OCB-O than to OCB-I. The results of analysis in Table 4 support hypothesis two. This implies that employee relationship management is more strongly related to the performance of OCB-O than to OCB-I. Also, the results of Pearson Correlation (Table 2) support hypothesis two. As can be seen by the results, the extent of relationship between the employee relationship management variables under study and OCB-O are greater than those between the employee relationship management variables under study and OCB-I. Thus, it appears that employees who perceive employee relationship management as not being fair are most likely to withhold those behaviours that benefit the organization as a whole, rather than to withhold those behaviors that directly benefit their colleagues. Conversely, when employees perceive employee relationship management as being fair, they are most likely to respond with behaviours that will benefit the organization. These findings are consistent with the findings of $[2,8,11]$.

\section{Managerial Implications}

The findings of this study suggest that good employee relationship management brings about increased employee performance of organizational citizenship behavior (OCB) in organisations. Thus, this study supports the idea that the outcomes of good employee relationship management lead to increase in organizational performance via OCB. This implies that managers should strive to build good relationships with employees and manage same properly to reap the benefits thereof. Some of these benefits include; employees will be more productive, more efficient, create less conflict and will be more loyal. This will translates into more revenue and satisfied customers. It is also a fact that improving employee relations will result in higher retention and reduced turnover rates, as a strong employee relations have a positive impact on the firm's growth and revenue. Employees who feel motivated and engaged in the workplace do an excellent job in their assigned roles, resulting in better products, greater customer satisfaction and increased sales.

\section{REFERENCES}

1. Kreitner, R., \& Kinicki, A. (2007). Organizational Behavior. 7th ed. McGraw-Hill Inc. New York
2. Purcell, J., \& Ahlstrand, W. (1994). Human resource management in the multi-divisional company. Oxford University press. UK

3. Clark, K. (2001). Leadership. Harvard University press. USA

4. Akpan, A. (2018). Organizational Citizenship Behaviour: Its nature, antecedents and consequences. Journal of Management, 21(2), 342361

5. Sonnentag, S., Volmer, J., \& Spychala, A. (2010). Job performance and OCB. Social Behaviour and Personality, 37(1), 281-299

6. Bolton, S. (2008). Searching for the human in human resource management. Theory, practice and workplace contexts. Palgrave Macmillan. USA

7. Bajaj, R., Sinha, S., \& Tiwari, V. (2013). Crucial Factors of Human Resource Management for Good Employee Relations: A Case Study. International Journal of Mining, Metallurgy \& Mechanical Engineering, 1(2), 90-92.

8. Jing, Z. (2013). Research on Employee Relationship Management of SMEs in china. Fifth international conference, (pp. 1-7). China.

9. Chukwudi, D. (2014). The impact of teamwork on organizational productivity. Retrieved on 28 Feb, 2020

from: http://nairaproject.com/projects/522.html

10. Hosmer, L. (1995). Trust: The connecting link between organizational theory and philosophical ethics. Academy of Management Review. 70, 379403

11. Organ, D. (1988). Organizationl Citizenship Behaviour: The good soldier syndrome. Lexington books. USA

12. Schnake, G. (1991). Affective response bias in the measurement of perceived task characteristics. Journal of Occupational Psychological, 1(1), 159166

13. Wayne, S. (1993). Commitment and Employee behaviour: Comparative of Affective Commitment and Continuance Commitment with perceived Organizational Support. The Journal of applied Psychology, 78; 774-780

14. Smith, D. (2013). Online social networking and office environmental factors that affect worker productivity. International Journal of procurement management, 6(5), 578-608.

15. Paine, J., \& Bachrach, D. (2000). Organizational Citizenship Behaviour: a critical review of the theoretical and empirical literature and suggestions for further research. Journal of Management, 26(3), 513-563

16. Kandlousi, N., Ali, A., \& Abdollahi, A. (2010). Organizational Citizenship Behaviour in concern of communication satisfaction: The role of formal and informal communication. International Journal of Business and Management, 5(10), 51-61

17. Gordon, D. (2003). Capitalist efficiency and socialist efficiency. Monthly review 3, 19-39 
Anietie Peter Akpan et al., Saudi J Econ Fin, Apr, 2021; 5(4): 164-172

18. Ferrin, D., \& Lee, C. (2006). The role of trust in Organizational settings. Organizational Science, 12, 450-467

19. Cook, J., \& Wall, T. (1980). New work attitude measures of trust, organizational commitment and personal need non fulfilment. Journal of occupational psychology. 53, 39-52.

20. Brief, A.P., \& Motowidlo, S.J. (1986). Prosocial Organizational Behaviours. Academy of Management Review, 11: 710-725

21. Allen, N., \& Meyer, J. (1993). Organizational Commitment scale: A cross-cultural application in Pakistan. Journal of Education and Vocational Research. 1(3), 80-86

22. Coleman, C. (1990). Managing labor relations in the public sector. San Francisco CA; Jossey-Bass

23. Flinders, N., \& Rauter, K. (2004). Organizational citizenship behaviors in relation to job status, job insecurity, organizational commitment and identification, job satisfaction. Management Decision, 46(6), 933-947

24. Meyer, P. (1995). Work characteristics and work attitude relations: moderating effects of attributions. Journal of Applied psychology, 75, 710- 720

25. Pareek, V., \& Rai, A. K. (2012). Building Relationship with Employees: An Employee Relationship Management Model. Journal of the Management Training Institute, 39(4), 32-37.

26. Riketta, M., \& Landerer, A. (2002). Organizational commitment, accountability and work behaviour: a correlational study. Social Behaviour and Personality, 30(7), 653-660
27. Jones, G., \& George, M. (1998). The experience and evolution of trust: Implications for cooperation and teamwork. Academy of Management review, 23(3), 531-540

28. Damian, G. (2008). Blurring Organizational boundaries and disordering hierarchies. Oxford. Oxford university press.

29. Anselem, A. (2017). Integral Community enterprise in Africa: Communitalism as an alternative to Capitalism. New York. Routledge

30. Cummings, L., \& Parks, J. (2015). Extra role behaviours: In pursuit of contructs and definitional clarity. Greenwich GT. JAI press.

31. Gefen, D., \& Carmeli, A. (2005). The relationship between work commitment models and employee withdrawal intentions. Journal of Managerial Psychology, 20(2), 63-85

32. Ogaard, T. (2008). Do organizational practices matter for hotel industry employees' jobs? A study of organizational practice archetypical configurations and job outcomes. International Journal of Hospitality Management, 25(4), 647-661

33. Sinha, S., \& Bajaj, R. (2013). Successful Human Resource Management Determinants to Build Good Employee Relations. International Journal of Human Resource Management and Research, 3(2), 31-36.

34. Williams, S., \& Anderson, P. (2011). Migration, immigration controls and the fashioning of precarious workers', work, employment and society. Journal of Management, 24(2), 17-30

35. Guffy, M., Rhodes, K., \& Rogin, P. (2005). Business communication: Process and product $5^{\text {th }}$ edition. Scarborough, ON. Thompson Nelson. 